\title{
Study on Spatial Difference of the Relationship between Regional Tourism and Economic Growth-Comparative Study of Guangzhou, Shenzhen and Zhuhai in Light of VAR Model
}

\author{
Yu Huang1, Mu Zhang2* \\ ${ }^{1}$ School of Management, Jinan University, Guangzhou, China \\ ${ }^{2}$ Shenzhen Tourism College, Jinan University, Shenzhen, China \\ Email: 'zhangmu@163.com
}

Received 3 February 2016; accepted 13 March 2016; published 16 March 2016

Copyright (C) 2016 by authors and Scientific Research Publishing Inc.

This work is licensed under the Creative Commons Attribution International License (CC BY).

http://creativecommons.org/licenses/by/4.0/

(c) (i) Open Access

\begin{abstract}
Based on the Eviews software and panel data of Guangzhou city, Shenzhen city and Zhuhai city, the study investigated the dynamic relationship between regional tourism and economic growth, using the methods including Cointegration Test, Granger Causality Test, VAR models and Variance Decomposition. The study result shows that there are long-term mutual effects between regional economic growth and regional tourism industry in each area. And in each area, the local GDP, Earning from International Tourism (EIT) and Earning from Domestic Tourism (EDT) have cointegration relationship. Moreover, in one certain area, the contribution rate of different factors to fluctuation of one variable changes over time.
\end{abstract}

\section{Keywords}

Economic Growth, Tourism Development, VAR Model, Cointegration Test, Granger Causality, Regional Differences, Panel Data

\section{Introduction}

Research on dynamics between tourism development and economic growth has received wide attention in recent

"Corresponding author.

How to cite this paper: Huang, Y. and Zhang, M. (2016) Study on Spatial Difference of the Relationship between Regional Tourism and Economic Growth-Comparative Study of Guangzhou, Shenzhen and Zhuhai in Light of VAR Model. American Journal of Industrial and Business Management, 6, 221-231. http://dx.doi.org/10.4236/ajibm.2016.63020 
years with the rapid development of tourism industry. However, either due to different temporal and spatial context or various methods deployed, conclusions of previous studies find much conflicting ideas or contradictions [1]. Currently, four major theories dominate international academic circles, they are: first, TLEG theory (tourism-led economic growth). The theory maintains tourism development that will produce positive spillover effect on foreign exchange, enterprise efficiency, employment, and scale economy, thus contributing to economic growth [2]-[6]; second, EDTG (economic-driven tourism growth) theory. Payne and Mervar, founder of the theory, think that good economic policies, government supervision and sufficient resources investment create a positive climate for tourism development [7]; third, BC (bidirectional causality) theory. The theory is formed based on the research conducted by Apergis [8], Chen [9], Lee [10] and Ribberstaat [11] in nine Caribbean coastal countries, South Korea, Non-OECD countries and Aruba, concluding that relationship between tourism development and economic growth features bidirectional causality; fourth, NC (non causality) theory. Figini [12] and Katircioglu [13] have put forward this theory from their studies.

Tourism-related research in China suffers late start because it is not until 1970s that tourism in China truly starts to become a industry and enjoys development. And correlation study of tourism industry and economic growth only starts from 2006 in China. Yang Yong [14], Chen Youlong [15] and Wu Zhongcai [16] have pointed out that there is no stable causality relation between economic growth and tourism development in China. Pang Li [17], Deng Zutao [18], Wang Jing [19] and Yang Min [20] have conducted research on the relationship between the two in light of regional perspective, taking provincial administrative regions of Hubei, Xinjiang and Fujian provinces as their research subject.

It can be concluded that traditional research on the relationship between tourism development and economic growth tends to be macro, static and absolute, heedless of the dynamic characteristics of the two's relation. That's why papers on spatial difference of the relationship between the two are rare to find. This paper, taking Guangzhou, Shenzhen and Zhuhai for research subject, has constructed a VAR model based on panel date collected so as to analyze spatial difference of the relationship between economic growth and tourism development. The results of the paper serve to provide strategic recommendations for economic construction and tourism development for Guangzhou, Shenzhen and Zhuhai as well as empirical experience for following studies by illuminating innovations of new perspective and method.

\section{Research Design and Data Stability Test}

The purpose of the study, which lies in correlation analysis of tourism development and economic growth in Guangzhou, Zhuhai and Shenzhen, necessitates choosing appropriate index to represent tourism development and economic growth. In reference to common method deployed in previous studies, the paper uses Gross Domestic Production (GDP) to represent economic growth; In light of diverse indexes to represent tourism development and taking into consideration data availability and statistic caliber reliability, the paper uses Earning from Domestic Tourism (EDT) and Earning from International Tourism (EIT) to represent tourism development. By consulting Guangdong Statistical Yearbook, China Tourism Statistics Yearbook and Guangdong Fifty Years (from 1949 to 1999) to collect relevant information related with the three previous mentioned indexes, the author of the paper has gathered panel date of Guangzhou, Shenzhen and Zhuhai from 1996 to 2012 (For convenience, the author has put prefix of GZ before variables related with Guangzhou, SZ for Shenzhen and ZH for Zhuhai respectively).

For avoidance of influence of factors such as inflation, exchange rate and heteroscedasticity of population and time series, the author has taken a series of counter-influence measures such as deflator adjustment, exchange rate conversion, choice of deflated value and per capita value as actual value, etc, and has applied logarithmic operation to the actual value per capita of the three indexes of Guangzhou, Shenzhen and Zhuhai each year and figured out corresponding data.

To lessen the data heteroscedasticity in the model (can only be lessened but not effaced) and better show the data correlation, the paper, before conducting unit root test for the data, has also applied logarithmic operation to the actual value of GDP per capita, actual value of EIT per capita and actual value of EDT per capita in Guangzhou, Shenzhen and Zhuhai and see the result in Table 1.

For avoidance of spurious regression in the process of forming VAR (Vector Auto Regression) model resulting from non-stationarity feature of series involved in the calculation, it is crucial to assess the non-stationarity feature of data series of Guangzhou, Shenzhen and Zhuhai (see Table 2). The paper, by deploying ADF method, has concluded that the first-order difference sequence of Shenzhen's data is stationary (integrated of 
Table 1. Result after being applied logarithmic operation.

\begin{tabular}{|c|c|c|c|c|c|c|c|c|c|}
\hline Year & GZLNGDP & GZLNEIT & GZLNEDT & SZLNGDP & SZLNEIT & SZLNEDT & ZHLNGDP & ZHLNEIT & ZHLNEDT \\
\hline 1996 & 9.085797 & 6.152087 & 7.028462 & 8.748393 & 5.675754 & 6.385823 & 9.340758 & 7.259487 & 7.400093 \\
\hline 1997 & 9.150674 & 6.164481 & 7.010226 & 8.815289 & 5.434125 & 6.341710 & 9.381684 & 7.208942 & 7.364041 \\
\hline 1998 & 9.218067 & 6.148871 & 7.132396 & 8.862091 & 5.415094 & 6.254433 & 9.428906 & 7.171044 & 7.350326 \\
\hline 1999 & 9.280893 & 6.181638 & 7.198842 & 8.913420 & 5.356988 & 6.219751 & 9.459145 & 7.186811 & 7.235276 \\
\hline 2000 & 9.337986 & 6.341393 & 7.190814 & 8.955956 & 6.025997 & 6.483113 & 9.506525 & 7.184144 & 7.326003 \\
\hline 2001 & 9.441073 & 6.405947 & 7.252991 & 9.057292 & 6.068809 & 6.513839 & 9.582538 & 7.251665 & 7.424040 \\
\hline 2002 & 9.554193 & 6.524184 & 7.340235 & 9.174242 & 6.138463 & 6.539145 & 9.674862 & 7.380325 & 7.561673 \\
\hline 2003 & 9.689495 & 6.356610 & 7.228757 & 9.308239 & 5.802748 & 6.354846 & 9.811539 & 7.280524 & 7.455207 \\
\hline 2004 & 9.812548 & 6.467083 & 7.378377 & 9.439196 & 6.058257 & 6.529312 & 9.915125 & 7.438768 & 7.643585 \\
\hline 2005 & 9.916727 & 6.614704 & 7.444409 & 9.546496 & 6.131256 & 6.579962 & 10.018541 & 7.627092 & 7.623440 \\
\hline 2006 & 10.041466 & 6.735321 & 7.497092 & 9.648730 & 6.155131 & 6.615571 & 10.147386 & 7.812593 & 7.771647 \\
\hline 2007 & 10.163906 & 6.784236 & 7.609281 & 9.740777 & 6.114408 & 6.656401 & 10.284190 & 7.722116 & 7.819884 \\
\hline 2008 & 10.266437 & 6.626420 & 7.673914 & 9.810219 & 6.065993 & 6.647976 & 10.347772 & 7.631087 & 7.933517 \\
\hline 2009 & 10.363850 & 6.755108 & 7.859051 & 9.869641 & 6.096983 & 6.731763 & 10.391162 & 7.695735 & 8.037659 \\
\hline 2010 & 10.473441 & 6.954986 & 8.032525 & 9.942918 & 6.147146 & 6.797855 & 10.499319 & 7.822616 & 8.316228 \\
\hline 2011 & 10.570081 & 6.896353 & 8.324689 & 10.029518 & 6.167554 & 6.881471 & 10.602077 & 7.587485 & 8.388099 \\
\hline 2012 & 10.660497 & 6.926957 & 8.515934 & 10.116864 & 6.254126 & 6.987520 & 10.660089 & 7.439080 & 8.513652 \\
\hline
\end{tabular}

Table 2. ADF test result of time series of Guangzhou, Shenzhen and Zhuhai.

\begin{tabular}{ccccc}
\hline Variables & T statistic & $\begin{array}{c}\mathbf{1 \%} \\
\text { Critical value }\end{array}$ & $\begin{array}{c}\mathbf{5 \%} \\
\text { Critical value }\end{array}$ & $\begin{array}{c}\mathbf{1 0 \%} \\
\text { Critical value }\end{array}$ \\
\hline GZLNGDP 2nd order difference & -3.505393 & -4.004425 & -3.098896 & -2.690439 \\
GZLNEIT 2nd order difference & -6.146516 & -4.200056 & -3.175352 & -2.728985 \\
GZLNEDT 2nd order difference & -5.247540 & -4.057910 & -3.119910 & -2.701103 \\
SZLNGDP 1st order difference & -4.178483 & -4.121990 & -3.144920 & -2.713751 \\
SZLNEIT 1st order difference & -5.038717 & -4.057910 & -3.119910 & -2.701103 \\
SZLNEDT 1st order difference & -5.872013 & -4.057910 & -3.119910 & -2.701103 \\
ZHLNGDP 2nd order difference & -4.517788 & -4.057910 & -3.119910 & -2.701103 \\
ZHLNEIT 2nd order difference & -4.225740 & -4.121990 & -3.144920 & -2.713751 \\
ZHLNEDT 2nd order difference & -4.061596 & -4.121990 & -3.144920 & -2.713751 \\
\hline
\end{tabular}

order 1); while in case of Guangzhou and Zhuhai, their data's second-order difference sequence is stationary, designated as (integrated of order 2). The author has chosen the stationary difference sequence of the three data group for late analysis so as to ensure the accuracy of the result.

\section{Johansen Co-Integration Test and Granger Causality Test}

In previous section, the paper has shown the stationary data series of Guangzhou, Shenzhen and Zhuhai by using ADF Test method and for avoidance of ambiguity, the author has listed the name of indexes that will be involved in the regression and their meanings are also presented (see Table 3).

\subsection{Johansen Co-Integration Test}

Yet, Co-Integration test is necessary before we start to form VAR model, as to ascertain whether long-term equilibrium relation among variables in the model exists or not. Thus, Johansen Co-Integration test is conducted by using Eviews software. The result is shown below (Tables 4-6). 
Table 3. Naming and definition of indexes.

\begin{tabular}{|c|c|c|}
\hline & Name & Definition \\
\hline \multirow{3}{*}{$\begin{array}{l}\text { Guangzhou } \\
\text { city }\end{array}$} & GZGDP & GZLNGDP 2nd order difference \\
\hline & GZEIT & GZLNEIT 2nd order difference \\
\hline & GZEDT & GZLNEDT 2nd order difference \\
\hline \multirow{3}{*}{$\begin{array}{l}\text { Shenzhen } \\
\text { city }\end{array}$} & SZGDP & SZLNGDP 1st order difference \\
\hline & SZEIT & SZLNEIT 1st order difference \\
\hline & SZEDT & SZLNEDT 1st order difference \\
\hline \multirow{3}{*}{$\begin{array}{c}\text { Zhuhai } \\
\text { city }\end{array}$} & ZHGDP & ZHLNGDP 2nd order difference \\
\hline & ZHEIT & ZHLNEIT 2nd order difference \\
\hline & ZHEDT & ZHLNEDT 2nd order difference \\
\hline
\end{tabular}

Table 4. Johansen co-integration test for GZ variables.

\begin{tabular}{|c|c|c|c|c|}
\hline \multicolumn{5}{|c|}{ Characteristic root tracing test } \\
\hline $\mathrm{CE}$ & $\mathrm{CV}$ & Trace statistic & 5\% Critical value & Prob.** \\
\hline None* & 0.939039 & 68.80668 & 35.01090 & 0.0000 \\
\hline At most $1^{*}$ & 0.842440 & 32.43900 & 18.39771 & 0.0003 \\
\hline At most $2^{*}$ & 0.476572 & 8.415630 & 3.841466 & 0.0037 \\
\hline \multicolumn{5}{|c|}{ Max-eigenvalue test } \\
\hline $\mathrm{CE}$ & $\mathrm{CV}$ & Max-Eigen & 5\% Critical value & Prob.** \\
\hline None* & 0.939039 & 36.36767 & 24.25202 & 0.0008 \\
\hline At most $1^{*}$ & 0.842440 & 24.02337 & 17.14769 & 0.0043 \\
\hline At most $2^{*}$ & 0.476572 & 8.415630 & 3.841466 & 0.0037 \\
\hline \multicolumn{5}{|c|}{ Standardization of cointegration vector } \\
\hline & GZEDT & GZGDP & GZEIT & \\
\hline & 1.000000 & -0.687341 & -0.517116 & \\
\hline & & $(0.37755)$ & $(0.04801)$ & \\
\hline
\end{tabular}

Table 5. SZGDP, SZEIT, SZEDT Johansen co-integration test for Shenzhen.

\begin{tabular}{|c|c|c|c|c|}
\hline \multicolumn{5}{|c|}{ Characteristic root tracing test } \\
\hline $\mathrm{CE}$ & $\mathrm{CV}$ & Trace statistic & 5\% Critical value & Prob.** \\
\hline None* & 0.869832 & 57.31706 & 35.01090 & 0.0001 \\
\hline At most $1^{*}$ & 0.750552 & 28.77208 & 18.39771 & 0.0013 \\
\hline At most $2^{*}$ & 0.486572 & 9.333025 & 3.841466 & 0.0023 \\
\hline \multicolumn{5}{|c|}{ Max-eigenvalue test } \\
\hline $\mathrm{CE}$ & $\mathrm{CV}$ & Max-Eigen & 5\% Critical value & Prob.** \\
\hline None* & 0.869832 & 28.54497 & 24.25202 & 0.0127 \\
\hline At most $1^{*}$ & 0.750552 & 19.43906 & 17.14769 & 0.0229 \\
\hline At most $2^{*}$ & 0.486572 & 9.333025 & 3.841466 & 0.0023 \\
\hline \multicolumn{5}{|c|}{ Standardization of cointegration vector } \\
\hline & SZEIT & SZGDP & SZEDT & \\
\hline & 1.000000 & -0.073628 & -2.031873 & \\
\hline & & $(0.11316)$ & $(0.04978)$ & \\
\hline
\end{tabular}


Table 6. ZHGDP, ZHEIT, ZHEDT Johansen co-integration test for Zhuhai.

\begin{tabular}{ccccc}
\hline & \multicolumn{4}{c}{ Characteristic root tracing test } \\
\hline CE & CV & Trace statistic & $5 \%$ Critical value & Prob.** \\
None* & 0.903956 & 57.39438 & 35.01090 & 0.0001 \\
At most 1* & 0.781349 & 26.93610 & 18.39771 & 0.0025 \\
At most 2* & 0.424046 & 7.172459 & 3.841466 & 0.0074 \\
\hline CE & CV & Max-eigenvalue test & Prob.** \\
None* & Max-Eigen & $5 \%$ Critical value & 0.0066 \\
At most 1* & 0.903956 & 30.45828 & 24.25202 & 0.0204 \\
At most 2* & 0.781349 & 19.76364 & 17.14769 & 0.0074 \\
\hline & 0.424046 & 7.172459 & 3.841466 & \\
\hline
\end{tabular}

Results show that, under the signification level of 5 percent, GDP, EIT and EDT of Guangzhou (GZEDT, GZGDP and GZEIT respectively), GDP, EIT and EDT of Shenzhen (SZEIT, SZGDP and SZEDT respectively) and GDP, EIT and EDT of Zhuhai (ZHEIT, ZHGDP and ZHEDT respectively) have co-integration relationship.

But by applying co-integration vector after standardization, difference surfaces among the long-term equilibrium equations of the three cities. The equations of the three cities are presented in Formula (1), Formula (2), and Formula (3).

$$
\begin{gathered}
\text { GZEDT }=0.687341 \text { GZGDP }+0.517116 \text { GZEIT } \\
\text { SZEIT }=0.073628 \text { SZGDP }+2.031873 \text { ZEDT } \\
\text { ZHEIT }=11.70409 \text { ZHGDP }+4.270640 Z \text { ZHEDT } .
\end{gathered}
$$

Therefore, in the long run:

For Guangzhou, every 1 percent increase of GDP growth brings 0.69 percent EDT growth; every 1 percent increase of EIT growth brings 0.52 EDT growth;

For Shenzhen, every 1 percent increase of GDP growth brings 0.07 percent EIT growth; every 1 percent increase of EDT growth brings 2.03 percent EIT growth;

For Zhuhai, every 1 percent increase of GDP growth brings 11.70 percent EIT growth; every 1 percent increase of EDT growth brings 4.27 percent EIT growth.

\subsection{Granger Causality Test}

Granger Causality test is applied to the variables of Guangzhou, Shenzhen and Zhuhai, by using Eviews software. Results are present in Tables 7-9.

As Table 7 shows, Granger Causality relationship is detected between GZGDP and GZEIT as well as between GZEIT and GZEDT. This means economic growth of Guangzhou will have positive impact for international tourism development; in the meanwhile, international tourism development of Guangzhou will contribute to domestic tourism development for Guangzhou.

As Table 8 shows, one-way Granger Causality relationship between SZEIT and SZGDP and bidirectional causality relationship between SZEIT and SZEDT is detected. This means international tourism development of Shenzhen will contribute to its economic growth; in the meanwhile, international tourism development and domestic tourism development of Shenzhen mutually benefit each other.

As Table 9 shows, four groups of Granger Causality relationship between ZHGDP and ZHEIT, ZHGDP and ZHEDT, ZHEIT and ZHGDP and ZHEDT and ZHEIT are detected. This means economic growth of Zhuhai will have positive impact for both international tourism and domestic tourism development; in the meanwhile, international tourism development contributes to economic growth of Zhuhai; and domestic tourism development 
Table 7. The results of granger causality test (Guangzhou city).

\begin{tabular}{cccc}
\hline Hypothesis & Observation & F-statistics & Prob. \\
\hline GZGDP does not Granger Cause GZEIT & 13 & 3.55244 & 0.0787 \\
GZEIT does not Granger Cause GZEDT & 12 & 8.46787 & 0.0210 \\
GZGDP does not Granger Cause GZEIT & 12 & 7.06214 & 0.0302 \\
GZEIT does not Granger Cause GZEDT & 11 & 17.2218 & 0.0556 \\
\hline
\end{tabular}

Table 8. The results of granger causality test (Shenzhen city).

\begin{tabular}{cccc}
\hline Hypothesis & Observation & F-statistics & Prob. \\
\hline SZEIT does not Granger Cause SZGDP & 15 & 7.79247 & 0.0163 \\
SZEIT does not Granger Cause SZGDP & 14 & 3.38208 & 0.0803 \\
SZEDT does not Granger Cause SZEIT & 14 & 3.15193 & 0.0917 \\
SZEDT does not Granger Cause SZEIT & 13 & 21.5258 & 0.0013 \\
SZEIT does not Granger Cause SZEDT & 13 & 8.89488 & 0.0126 \\
\hline
\end{tabular}

Table 9. The results of granger causality test (Zhuhai city).

\begin{tabular}{|c|c|c|c|}
\hline Hypothesis & Observation & F-statistics & Prob. \\
\hline ZHGDP does not Granger Cause ZHEIT & 14 & 4.27328 & 0.0631 \\
\hline ZHEIT does not Granger Cause ZHGDP & 14 & 13.6899 & 0.0035 \\
\hline ZHEIT does not Granger Cause ZHGDP & 13 & 5.69247 & 0.0290 \\
\hline ZHEDT does not Granger Cause ZHEIT & 11 & 29.8551 & 0.0327 \\
\hline ZHGDP does not Granger Cause ZHEDT & 11 & 10.3556 & 0.0900 \\
\hline
\end{tabular}

of Zhuhai will have positive impact on international tourism development of Zhuhai.

In conclusion, regardless of what research subject we choose, Guangdong Province or Guangzhou, Shenzhen and Zhuhai cities, the Granger Causality test results all indicate complexity of causality relation among variables. Basically, economic growth and tourism development mutually influence and benefit each other, and their relationship will change within different monitoring scope (lag phase).

\section{Forming VAR Model}

Researchers shall go through “Order setting-Formation-Stability Test” stages to form VAR model, with setting appropriate order being the most important step, which is the lag phase of the model.

From Table 10, three of LR, FRE, AIC, SC, HQ falls into the Period 0 of lag phase, and two of them falls into Period 2 of lag phase. To give the VAR model more substantial meaning, we choose Period 2 to form VAR model for Guangzhou

A formula is concluded for Guangzhou VAR model (Table 11)

$$
\begin{aligned}
& {\left[\begin{array}{c}
\text { GZGDP }_{t} \\
\text { GZEIT }_{t} \\
\text { GZEDT }_{t}
\end{array}\right]=\left[\begin{array}{l}
0.003659 \\
0.031010 \\
0.035212
\end{array}\right]+\left[\begin{array}{ccc}
-0.121024 & 0.061832 & -0.091986 \\
-0.684292 & -0.745881 & -0.112361 \\
-0.318713 & -0.088741 & -0.781388
\end{array}\right]\left[\begin{array}{l}
\text { GZGDP }_{t-1} \\
\text { GZEIT }_{t-1} \\
\text { GZEDT }_{t-1}
\end{array}\right]+} \\
& {\left[\begin{array}{ccc}
0.087500 & 0.035343 & -0.045255 \\
-6.139782 & -0.939752 & 0.273594 \\
-2.257841 & 0.094195 & -0.580675
\end{array}\right]\left[\begin{array}{c}
\mathrm{GZGDP}_{t-2} \\
\mathrm{GZEIT}_{t-2} \\
\mathrm{GZEDT}_{t-2}
\end{array}\right]+\varepsilon_{t}}
\end{aligned}
$$

Afterwards, we apply stability test to the model by using AR unit root test, the result is shown in Figure 1.

According to Figure 1, all the reciprocal value of characteristic root of Guangzhou VAR model falls with the scope of unit circle. Therefore, stability exists in the model we have formed and thus the prerequisite for late variance decomposition analysis is established. 
Table 10. Choosing order for Guangzhou VAR model.

\begin{tabular}{ccccccc}
\hline Lag & LogL & LR & FPE & AIC & SC & HQ \\
\hline 0 & 49.11092 & NA* & $1.67 \mathrm{e}-07^{*}$ & -7.093988 & $-6.963615^{*}$ & -7.120785 \\
1 & 57.08802 & 11.04522 & $2.07 \mathrm{e}-07$ & -6.936619 & -6.415127 & -7.043809 \\
2 & 69.00334 & 10.99876 & $1.82 \mathrm{e}-07$ & $-7.385130^{*}$ & -6.472519 & $-7.572712^{*}$ \\
\hline
\end{tabular}

Table 11. Parameter output for Guangzhou VAR (2) model.

\begin{tabular}{|c|c|c|c|}
\hline & GZGDP & GZEIT & GZEDT \\
\hline \multirow[t]{3}{*}{ GZGDP $(-1)$} & -0.121024 & -0.684292 & -0.318713 \\
\hline & $(0.44411)$ & (2.90355) & (1.76062) \\
\hline & {$[-0.27251]$} & {$[-0.23567]$} & {$[-0.18102]$} \\
\hline \multirow[t]{3}{*}{ GZGDP $(-2)$} & 0.087500 & -6.139782 & -2.257841 \\
\hline & $(0.42586)$ & (2.78419) & (1.68824) \\
\hline & {$[0.20547]$} & {$[-2.20523]$} & {$[-1.33739]$} \\
\hline \multirow[t]{3}{*}{ GZEIT $(-1)$} & 0.061832 & -0.745881 & -0.088741 \\
\hline & $(0.04603)$ & $(0.30092)$ & $(0.18247)$ \\
\hline & [1.34337] & {$[-2.47867]$} & {$[-0.48634]$} \\
\hline \multirow[t]{3}{*}{ GZEIT $(-2)$} & 0.035343 & -0.939752 & 0.094195 \\
\hline & $(0.06860)$ & $(0.44850)$ & $(0.27196)$ \\
\hline & [0.51519] & {$[-2.09530]$} & [0.34636] \\
\hline \multirow[t]{3}{*}{ GZEDT $(-1)$} & -0.091986 & -0.112361 & -0.781388 \\
\hline & $(0.08801)$ & $(0.57537)$ & $(0.34888)$ \\
\hline & {$[-1.04524]$} & {$[-0.19529]$} & {$[-2.23968]$} \\
\hline \multirow[t]{3}{*}{ GZEDT $(-2)$} & -0.045255 & 0.273594 & -0.580675 \\
\hline & (0.10194) & $(0.66648)$ & $(0.40413)$ \\
\hline & {$[-0.44394]$} & [0.41051] & {$[-1.43684]$} \\
\hline \multirow[t]{3}{*}{$\mathrm{C}$} & 0.003659 & 0.031010 & 0.035212 \\
\hline & $(0.00686)$ & $(0.04483)$ & $(0.02718)$ \\
\hline & {$[0.53360]$} & [0.69174] & [1.29536] \\
\hline
\end{tabular}

Inverse Roots of AR Characteristic Polynomial

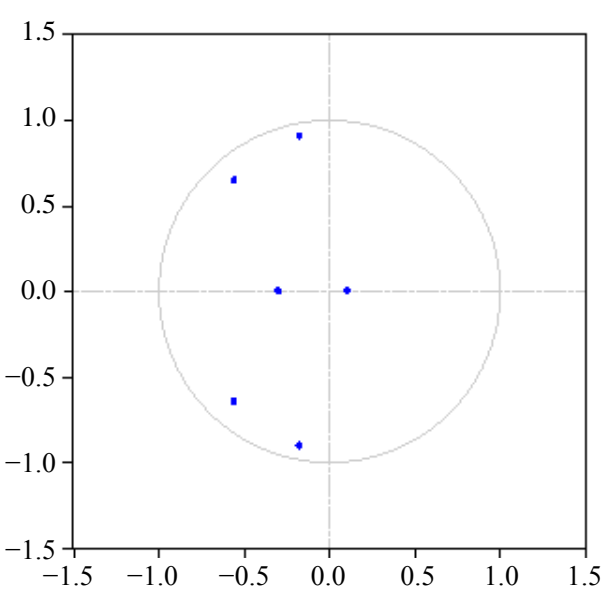

Figure 1. VAR stability test result for Guangzhou VAR model. 
Following the track of the VAR model formation for Guangzhou and stability test shown before, formula of VAR model for Shenzhen and Zhuhai, having undergone stability test, are also formed.

$$
\begin{aligned}
& {\left[\begin{array}{c}
\mathrm{SZGDP}_{t-1} \\
\text { SZEIT }_{t} \\
\text { SZEDT }_{t}
\end{array}\right]=\left[\begin{array}{l}
0.034314 \\
0.192310 \\
0.045439
\end{array}\right]+\left[\begin{array}{lll}
1.103006 & 0.144266 & -0.218296 \\
1.322413 & 1.075879 & -2.539996 \\
2.462924 & 0.787265 & -1.659365
\end{array}\right]\left[\begin{array}{c}
\mathrm{SZGDP}_{t-1} \\
\mathrm{SZEIT}_{t-1} \\
\mathrm{SZEDT}_{t-1}
\end{array}\right]+} \\
& {\left[\begin{array}{ccc}
-0.338357 & -0.072930 & 0.165522 \\
-0.088763 & 0.409542 & -1.591772 \\
-2.111109 & -0.394504 & 0.319134
\end{array}\right]\left[\begin{array}{c}
S Z G D P_{t-2} \\
S Z E I T_{t-2} \\
S Z E D T_{t-2}
\end{array}\right]+} \\
& {\left[\begin{array}{ccc}
-0.126807 & 0.014087 & -0.022277 \\
-1.730999 & -1.914368 & 2.653152 \\
0.137699 & -1.122051 & 1.689280
\end{array}\right]\left[\begin{array}{c}
S_{S G D P_{t-2}} \\
S_{S Z E I T_{t-2}} \\
S Z E D T_{t-2}
\end{array}\right]+\varepsilon_{t}} \\
& {\left[\begin{array}{c}
\text { ZHGDP }_{t} \\
\text { ZHEIT }_{t} \\
\text { ZHEDT }_{t}
\end{array}\right]=\left[\begin{array}{l}
0.003403 \\
0.003437 \\
0.020437
\end{array}\right]+\left[\begin{array}{ccc}
0.163116 & 0.212808 & -0.070984 \\
-2.403966 & -0.161316 & -0.368447 \\
-0.448128 & 0.144155 & -0.857408
\end{array}\right]\left[\begin{array}{c}
\text { ZHGDP }_{t-1} \\
\text { ZHEIT }_{t-1} \\
\text { ZHEDT }_{t-1}
\end{array}\right]+\varepsilon_{t} \text {. }}
\end{aligned}
$$

\section{Variance Decomposition}

Based on the VAR models, variance decomposition is applied. The purpose of the variance decomposition is to analyze the contribution rate of endogenous variables to structural impact within different periods; in essence, to describe the different contribution rate, in the form of percentage, of all the variables with one region to bring out the fluctuation of one variable in the VAR model. By using Eviews software, variance decomposition operation is conducted. And the results for Guangzhou, Shenzhen and Zhuhai VAR models are shown (Figures 2-4).
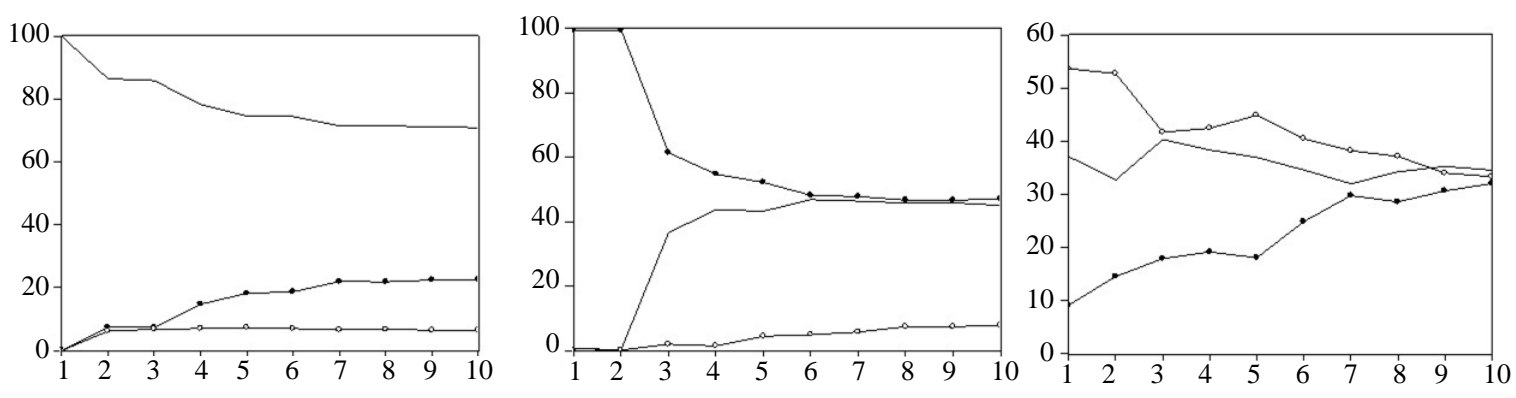

- GZGDP $\multimap-$ GZEIT $\multimap-$ GZEDT
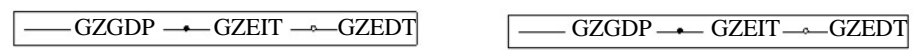

Figure 2. Variance decomposition of GZGDP, GZEIT, GZEDT.
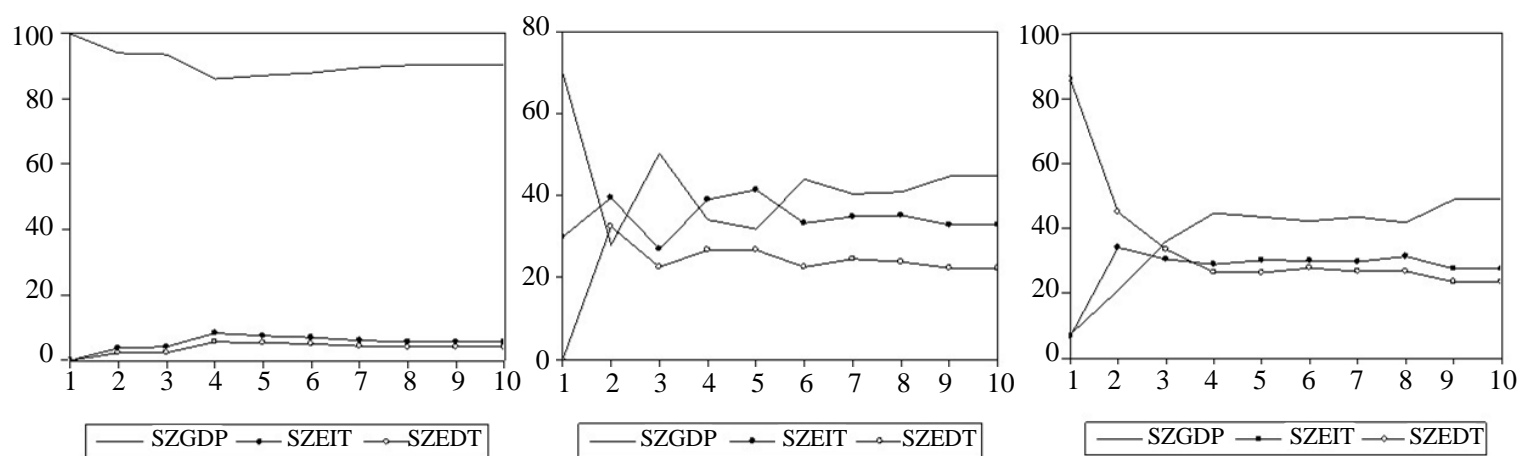

Figure 3. Variance decomposition of SZGDP, SZEIT, SZEDT. 

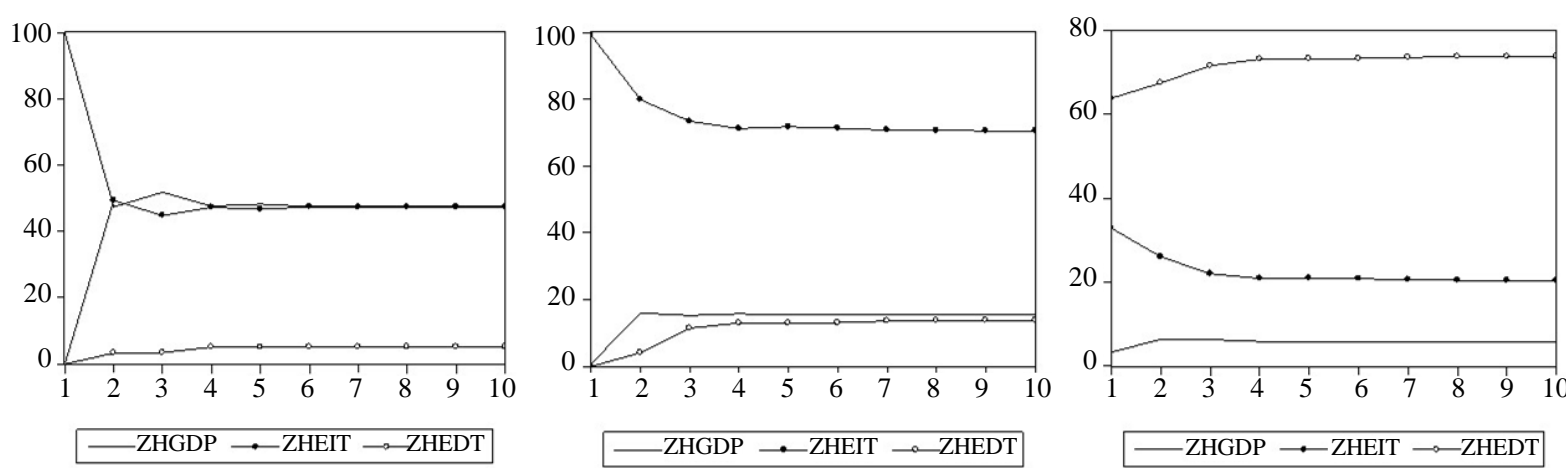

Figure 4. Variance decomposition of ZHGDP, ZHEIT, ZHEDT.

According to Figure 2: (1) GDP fluctuation of Guangzhou, in the first period, results exclusively from intrinsic factors, while the intrinsic factors have weaken effect on the GDP fluctuation and only account for $70 \%$ for the fluctuation in the last period. And the international tourism and domestic tourism have shown and strengthened their influence on GDP starting from Period 2 and their contribution to GDP have exceeded 20\% and 6\% respectively in the last period; (2) International Tourism fluctuation of Guangzhou, in the first period, results both from GDP and its intrinsic factors, with minor contribution of GDP. However, from Period 2 to Period 3, GDP has significant rise in affecting International Tourism and maintains a level of over $40 \%$. EDT of Guangzhou has shown and strengthened its effect on international tourism starting from Period 2 and its contribution accounts for 7\% in the last period; (3) Starting from first period, Domestic Tourism fluctuation of Guangzhou, is caused by economic growth, international growth and its intrinsic factors, with its intrinsic factors as major contributing factor, accounting for over $50 \%$ of the contribution. As with the rise of the contribution of GZGDP and GZEIT to the growth of GZEDT, intrinsic factors' contribution to the growth of GZEDT declines steadily. And the three have almost same contribution rate towards the growth of GZEDT in the last period.

According to Figure 3: (1) GDP fluctuation of Shenzhen, in the first period, results exclusively from intrinsic factors, with high contribution rate of about $90 \%$. And the international tourism and domestic tourism have shown their influence on economic growth only starting from Period 2 and reach the highest point in Period 4; (2) Variance decomposition of Shenzhen's EIT shows complex outcome, with the contribution rate of all the three contributing factors fluctuates dramatically and they start to stabilize only starting from last three periods. In Period 2, the contribution rate of SZEDT to SZEIT is over 30\% and it starts to fall afterwards. In last three periods, SZGDP, SZEIT's intrinsic factors and SZEDT have stabilized their contribution to SZEIT, with contribution rate of about $40 \%, 30 \%$ and $20 \%$ respectively; (3) EDT fluctuation of Shenzhen, starting from first Period, is caused by SZGDP, SZEIT and its intrinsic factors, with intrinsic factors having most contribution rate of about 86\%. While in the Period 2 and 3, intrinsic factors' contribution to SZEDT declines and that of the other two contributing factors rises considerably. Starting from Period 4, contribution rate of SZGDP, SZEIT and SZEDT stabilizes, with $45 \%$, $30 \%$ and $25 \%$ respectively.

According to Figure 4: (1) GDP fluctuation of Zhuhai, in the first period, results exclusively from intrinsic factors. However, starting from Period 2, contribution rate of international tourism to GDP rises dramatically to about 50\%. From Period 2 to last Period, contribution rate of ZHEIT and intrinsic factors to ZHGDP maintain same level and that of ZHEDT is no more than 5.2\% thorough; (2) EIT fluctuation of Zhuhai, in the first period, results from contribution of ZHGDP and its intrinsic factors and the contribution rate of ZHGDP is less than 1\%. While from Period 2 to Period 3, the intrinsic factors have less and less contribution to ZHEIT and that of ZHGDP and ZHEDT climbs. From Period 4 to last Period, contribution rate the three contributing factors to ZHEIT stabilizes, with GDP, EIT's intrinsic factors and EDT of 15\%, 70\% and 15\% respectively; (3) EDT fluctuation of Zhuhai, starting from the first period, is caused by ZHGDP, ZHEIT and its intrinsic factors, with its intrinsic factors contributing most, over 60\%. After first period, contribution of ZHGDP starts to rise while it maintains at the level of about $6 \%$. Contribution of EIT falls in the first three periods and keeps at the level of about $20 \%$ until the last period. Contribution of its intrinsic factors rises in the first three periods and keeps at the level of about $70 \%$ until the last period.

From the analysis of variance decomposition, it is concluded that the fluctuation of every variables in the VAR model is affected by contribution of different factors and the contribution rate of each factor would change 
over time, showing totally different characteristics in different periods. This, to some degrees, it is necessary and important to introduce the perspective of temporal and spatial difference into the study of the relationship between regional economic growth and tourism development.

\section{Conclusions and Recommendations}

Based on time sequence and VAR model, and using Eviews software, the author of the paper aims to analyze and compare the dynamic relationship between economic growth and tourism development in Guangzhou, Shenzhen and Zhuhai respectively. Study results show that in the long run, economic growth and tourism development in the three cities show bidirectional causality relationship and mutually influence each other; GDP, EIT and EDT of the three cities all have co-integration relationship and the contribution rate of the other two variables and the intrinsic factors of the third variable to the fluctuation of the third factor would change over time.

Recommendations concerning economic construction and tourism development in Guangzhou, Shenzhen and Zhuhai are proposed in light of regional difference.

(1) A scientific concept of development should be established in coordinating economic growth and tourism development. On the one hand, policy-makers shall bear in mind that economic growth and tourism development are closely related with each other and they should take advantage of the interaction between the two so as to promote development and avoid lopsided development; on the other hand, short-sighted actions should be avoided. Policy-makers shall acknowledge that economic growth, tourism development and all the factors affecting the development of the two are not static and we should analyze their laws of development.

(2) In the long term, economic growth and domestic tourism development of Shenzhen and Zhuhai have great impact on international tourism growth. Therefore, in Shenzhen and Zhuhai, on one hand, policy-makers shall bear in mind the fundamental position of economic growth and hold on to the first and foremost task of economic construction so as to attract international tourists and create good environment for tourism development; on the other hand, we should also spare no efforts in investing in tourism, developing distinctive tourism resources and improving tourism service facilities so as to create brand effect of regional tourism.

(3) Also in the long run, economic growth and international tourism development of Guangzhou have great contrition to domestic tourism development. Therefore, in the process of coordinating economic growth and tourism development in Guangzhou, the first and foremost task of economic construction should also be unremittingly carried out and investment should be made to within-city tourism and improve tourism sites, transportation and hotels so as to attract domestic tourists; on the other hand, we should take advantage of long history and characteristic cultural resources of Guangzhou, make them known to international tourists, and create international brand.

\section{References}

[1] Tang, C.-H.H. and Jang, S.S. (2009) The Tourism-Economy Causality in the United States: A Sub-Industry Level Examination. Tourism Management, 30, 553-558. http://dx.doi.org/10.1016/j.tourman.2008.09.009

[2] Schubert, S.F., Brida, J.G. and Risso, W.A. (2011) The Impacts of International Tourism Demand on Economic Growth of Small Economies Dependent on Tourism. Tourism Management, 32, 377-385. http://dx.doi.org/10.1016/j.tourman.2010.03.007

[3] Brida, J.G. and Pulina, M. (2010) A Literature Review on the Tourism-Led-Growth Hypothesis. Centro di Ricerche Economiche NOrd e Sudd (CRENoS), Working Paper 17.

[4] Balaguer, J. and Cantavella-Jorda, M. (2002) Tourism as a Long-Run Economic Growth Factor: The Spanish Case. Applied Economics, 34, 877-884. http://dx.doi.org/10.1080/00036840110058923

[5] Andriotis, K. (2002) Scale of Hospitality Firms and Local Economic Development-Evidence from Crete. Tourism Management, 23, 333-341. http://dx.doi.org/10.1016/S0261-5177(01)00094-2

[6] Croes, R.R. (2006) A Paradigm Shift to a New Strategy for Small Island Economies: Embracing Demand Side Economics for Value Enhancement and Long Term Economic Stability. Tourism Management, 27, 453-465. http://dx.doi.org/10.1016/j.tourman.2004.12.003

[7] Payne, J.E. and Mervar, A. (2010) Research Note: The Tourism-Growth Nexus in Croatia. Tourism Economics, 16, 1089-1094. http://dx.doi.org/10.5367/te.2010.0014

[8] Apergis, N. and Payne, J.E. (2012) Research Note: Tourism and Growth in the Caribbean Evidence from a Panel Error Correction Model. Tourism Economics, 18, 449-456. http://dx.doi.org/10.5367/te.2012.0119 
[9] Chen, C.-F. and Chiou-Wei, S.Z. (2009) Tourism Expansion, Tourism Uncertainty and Economic Growth: New Evidence from Taiwan and Korea. Tourism Management, 30, 812-818. http://dx.doi.org/10.1016/j.tourman.2008.12.013

[10] Lee, C.-C. and Chang, C.-P. (2008) Tourism Development and Economic Growth: A Closer Look at Panels. Tourism Management, 29, 180-192. http://dx.doi.org/10.1016/j.tourman.2007.02.013

[11] Ridderstaat, J., Croes, R. and Nijkamp, P. (2013) Tourism and Long-Run Economic Growth in Aruba. International Journal of Tourism Research, 16, 472-487.

[12] Figini, P. and Vici, L. (2010) Tourism and Growth in a Cross-Section of Countries. Tourism Economics, 16, 789-805. http://dx.doi.org/10.5367/te.2010.0009

[13] Katircioglu, S.T. (2009) Revisiting the Tourism-Led-Growth Hypothesis for Turkey Using the Bounds Test and Johansen Approach for Cointegration. Tourism Management, 30, 17-20. http://dx.doi.org/10.1016/j.tourman.2008.04.004

[14] Yang, Y. (2006) An Empirical Analysis of the Relationship between Tourism and Economic Growth in China. Tourism Science, 20, 40-46.

[15] Chen, Y.L. (2005) Theoretical and Empirical Research on the Relationship between Tourism Development and Economic Growth in our Country. Hunan University.

[16] Wu, Z.C. (2007) The Contribution of Inbound Tourism to Economic Growth in China. Journal of Beijing International Studies University, 9, 30-33.

[17] Pang, L., Wang, Z. and Liu, Q.C. (2006) Research on the Relationship between International Tourism and Economic Growth in China. Areal Research and Development, 25, 51-55.

[18] Deng, Z.T. and Lu, Y.Q. (2008) An Empirical Analysis of the Relationship between Tourism and Economic Growth in Hubei Province. Statistics and Decision, 17, 95-97.

[19] Wang, J. (2007) An Empirical Analysis of the Relationship between Tourism and Economic Growth in Fujian Province. Economic and Social Development, 5, 73-75.

[20] Yang, M. and Luo, H. (2008) Relationship between Tourism and Economic Growth. Resources \& Industries, 10, 8386. 